\title{
ESCREVER O PODER OS AUTOS DE VASSALAGEM E A VULGARIZAÇÃO DA ESCRITA ENTRE AS ELITES AFRICANAS NDEMBU*
}

\author{
Catarina Madeira Santos \\ Centro de História de Além-Mar, Universidade Nova de Lisboa. \\ Pos-doutorado associado do Ceaf - Centre d'études africaines - EHESS.
}

\begin{abstract}
Resumo
Em trabalhos recentes foi posta em evidência a importância do uso da escrita para a construção da história de Angola, por meio do exemplo exuberante dos Estados Ndembu. Sem abandonar os problemas associados à escrita, procuramos centrar-nos na segunda metade do século XVIII e primeiras décadas do XIX, para dar conta de uma articulação entre política colonial e sedimentação de uma linguagem burocrática que estrutura as relações entre poderes constituídos e reconhecidos entre si. Burocracias coloniais e burocracias africanas, rotas burocráticas assentes numa retórica fina, dão-se a conhecer em documentação que cobre uma área geográfica vasta (governos de Angola e Benguela) e uma hierarquia institucional ampla (desde o Conselho Ultramarino aos documentos dos sobados, passando pelos capitães-mores dos presídios).
\end{abstract}

\section{Palavras-Chave}

Angola $\bullet$ Elites africanas • Escrita • Burocracia • Administração Colonial

\section{Abstract}

In recent works it has been brought up to evidence the importance of the writen registers especially through the exuberant example of the Ndembu States. Without abandoning the problems concerning written processes we are focusing on the second half of the XVII century and the two first decades of the XIX century in order to apprehend the articulation between colonial politics and the sedimentation of a bureaucratic language that structures the relations between the constituted and recognizable powers. Bureaucratic colonies, and African bureaucracies, bureaucratic routes/directions settled down on a fine rhetoric give themselves to light through the documentation that covers an wide geographic area (Angola and Benguela governments) and a vast institutional hierarchy (from the Ultramarine Counselor to the Sobados' documents, passing by the penitentiary of Capitães-Mores).

\section{Keywords}

Angola $\bullet$ African Elites $\bullet$ Written $\bullet$ Bureaucracy $\bullet$ Colonial Administration

\footnotetext{
"Este texto corresponde à comunicação feita ao Annual Meeting of the Society for Spanish and Portuguese Historical Studies (SSPHS), 2000, University of New York , "Escrever o poder. Os autos de vassalagem e a vulgarização da escrita entre os africanos (Angola, séculos XVII-XX)", retomada em 2003, no International Symposium, Angola on the Move: Transport Routes, Communications and History, Centre for Modern Oriental Studies, Berlim.
} 
Para a historiografia é ponto assente que as sociedades africanas ditas tradicionais, e distanciadas da influência do islamismo, se definem como sociedades da oralidade, uma vez que nunca usaram a escrita e se organizaram à margem das implicações dessa cultura. A ausência de fontes escritas africanas remeteria, assim para uma eficiente articulação entre a documentação de origem colonial e a recolha, no terreno, da tradição oral, sem deixar de recorrer aos contributos concertados da arqueologia e da antropologia.

O objectivo geral deste texto é precisamente o de questionar a dicotomia estabelecida, e aceite, entre sociedades com escrita e sociedades sem escrita, a que costumam andar ligados dois outros conceitos dicotómicos, já muito explorados e discutidos por várias escolas de historiadores e antropólogos - o de sociedades com Estado e sociedades sem Estado. Para isso, partirei da análise do caso específico de um conjunto de formações políticas africanas de pequena dimensão, os Ndembu ou Dembos, que se encontravam localizadas no Norte de Angola, ao longo da linha do rio Kwanza, provavelmente desde antes do século XVII. Sem abandonarem a sua estrutura política e social original, mantiveram um contacto secular com estados que dispunham de estruturas políticas e burocráticas estabelecidas sobre a escrita: as autoridades coloniais portuguesas (sedeadas em Luanda) e, por imitação destas, o Reino do Congo, com quem os Ndembu mantinham uma antiga dependência política. A sua história está documentada desde o século XVII até ao século XX, permitindo-nos acompanhar as etapas em que se estruturou o processo que conduziu à apropriação da escrita, assim como a forma como viria a resultar, numa fase mais adiantada, a configuração de um fenómeno singular: a utilização da escrita em contextos puramente africanos, quer dizer, na relação entre poderes africanos e à volta de assuntos locais (v.g. linhagens ${ }^{1}$ ) a par de uma certa "aprendizagem do Estado burocrático", visível num desenvolvimento original de um aparelho político, em que ao lado do tradicional conselho dos macotas e de instituições não políticas, como as linhagens, se impuseram estruturas directamente decalcadas da administração colonial (os secretários e os Arquivos de Estado). O processo colonial e de colonização em África, normalmente associado pela historiografia ao tráfico de escravos e também ao mundo atlântico oferece dimensões que,

${ }^{1}$ Cf. SANTOS, Catarina Madeira e TAVARES, Ana Paula Tavares. Africae Monumenta. A apropriação da escrita pelos africanos. Arquivo Caculo Cacahenda, Lisboa, IICT, 2002, p. 20 e ss. 
embora possam e devam ser referidas a essa grande matriz, divergem dela e configuram fenómenos sócio-culturais a que convém reconhecer alguma autonomia, quer dizer, fenómenos cuja história, na longa duração, se passa a definir mais em relação às razões africanas do que em relação ao contexto exterior onde têm origem. $\mathrm{O}(\mathrm{s})$ uso(s) da escrita, como se verá, não estão apenas dependentes das relações que se estabelecem com o poder colonial, pelo contrário, progressivamente (e isto ao longo do século XIX), a escrita começa a participar do corpus de saberes das elites Ndembu, não como dado exterior mas como dado interior, e interage com esse mesmo corpus. Só assim se percebe que se chegue a uma formulação tão inesperada como a de "carta com feitiço", quando a própria escrita se transforma em sagrado, numa associação que revela a inscrição da escrita que vem de fora num contexto especificamente africano. ${ }^{2}$

O que tem interesse fazer ressaltar neste estudo de caso é a possibilidade de reconstituir o processo pelo qual os Ndembu entraram em contacto com a cultura escrita para, a partir daí, perceber uma contiguidade histórica entre oralidade e escrita, atestando assim que uma análise a partir de esquemas excessivamente bipolares e, portanto, claramente empobrecedores, (maxime sociedades com escrita/sociedades sem escrita, ou ainda a idéia de que a escrita é uma técnica neutral cujos efeitos nas várias sociedades serão sempre os mesmos ${ }^{3}$ )

\footnotetext{
${ }^{2}$ SANTOS, Catarina Madeira e TAVARES, Ana Paula. Africae Monumenta, p. 20; nesta mesma publicação ver o documento número 195, referente correspondência entre D. Sebastião Agombe, Dembo Quilumbo Quiacongo e o Dembo Caculo Cazenga (29 de Fevereiro de 1913).

${ }^{3}$ Sobre este último aspecto vide tudo o que se tem escrito na área dos New Literacy Studies, em especial STREET, B. Literacy in Theory and Practice. Cambridge: CUP, 1984; STREET, B. "Literacy practices and literacy myths." In SALJO, R. (Ed.) The Written Word: Studies in Literate Thought and Action, Springer-Verlag Press, 59-72, 1988; STREET, B. Social Literacies. London: Longman, 1995; STREET, B. "Literacy Events and Literacy Practices". In MARTIN-JONES, M. \& JONES, K. (Ed.) Multilingual Literacies: Comparative Perspectives on Research and Practice, Amsterdam: John Benjamin's, 17-29, 2000; STREET, B. (ed). Literacy and Development: ethnographic perspectives, Routledge, London, 2001. O trabalho de Street se iniciou com a formulação da noção de multiple literacies e que faz a distinção entre o "modelo autónomo" e o "modelo ideológico" da literacia e ainda entre o que são acontecimentos e práticas da literacia. Esta escola critica uma perspectiva, muitas vezes adoptada, que parte do pressuposto de que a capacidade de ler e escrever em si mesma autonomamente - terá sempre o mesmo tipo de efeitos quando transplantada de um determinado contexto (sociedade) para outros contextos (ou sociedades) onde estão presentes práticas sociais e cognitivas específicas e portanto diferentes. Numa perspectiva mais tradicional, veicula-se a ideia de que a introdução da literacia em certas camadas populacionais terá como efeito o enaltecer de capacidades cognitivas, a promoção de oportunidades económicas, fazendo aí crescer melhores cidadãos, em comparação com as circunstancias anteriores marcadas
} 
nem sempre dá cobertura à "realidade" que está diante dos olhos do historiador. Talvez por isso mesmo, porque as rotinas historiográficas acabam por conduzir, mais ou menos inconscientemente, para direcções conhecidas e sancionadas pela "autoridade das academias", o caso específico dos Ndembu, e da sua relação com a escrita, tenha sido sucessivamente escamoteado, eu diria até, "tornado invisível", por aqueles que, ao compulsaram códices e documentação avulsa, onde o uso da escrita pelos africanos estava presente, e bem à vista, não reconheceram aí um objecto de estudo de corpo inteiro, autónomo daqueles que eram, e de alguma maneira continuam a ser, os grandes temas canónicos.

pela iliteracia. É a esta perspectiva que Street chama um modelo autónomo de literacia. De alguma maneira os trabalhos de Jack Goody, com toda a importância que se lhe deve reconhecer, nomeadamente por reconhecer na escrita e à escrita o estatuto de objecto no campo historiográfico, remetem um pouco para esta ideia de que a escrita em si e por si produz certos efeitos sociais (GOODY, Jack, 1988. Domesticação do pensamento selvagem. Lisboa: Editorial Presença; GOODY, Jack, 1994, Entre L'Oralité et L'écriture, Paris, P.U.F.). Quer dizer, independentemente dos contextos, os seus efeitos seriam similares, uma vez que a literacia arrastaria consigo um processo neutral e universalmente válido de transformação e, de alguma maneira de aproximação ao cânone ocidental e ocidentalizante. O modelo de análise proposto pelos New Literacy Studies sugere que, na pratica, a literacia varia de um contexto para outro e assim também os seus efeitos nos diferentes contextos em que ocorre. Critica o tal "modelo autónomo" denunciando como ele decorre do facto de se proceder a uma projecção simplista das concepções ocidentais para outras culturas. Em alternativa aponta o "modelo ideológico" de literacia, onde se oferece uma perspectiva mais cultural e também mais fina, no sentido de mais apurada das práticas que lhe andam associadas e onde se trazem à luz as variabilidades contextuais. Afinal a escrita em si mesma uma prática social e não um mero instrumento técnico ou neutral e como tal inscreve-se em, e relaciona-se com, concepções de saber e identidade. A literacia é um saber social em permanente interacção com o corpus de saberes de que cada sociedade dispõe e a que faz recurso (sobre este último ponto vide GEE, Social Linguistics: Ideology in Discourses. London: Falmer Press, 1991; GEE, 'The New Literacy Studies; form "socially situated" to the work of the social', In: BARTON, D., HAMILTON, M. and IVANIC, R. Situated Literacies: reading and writing in context. London: Routledge, 2000, pp. 180-196; e também BARTON, D., HAMILTON, M. e IVANIC, R., Situated Literacies: reading and writing in context. London: Routledge, 2000). Numa outra perspectiva, que procura fazer uma etnologia das escritas do quotidiano, e em especial um inquérito etnográfico das praticas da escrita dos ciganos - uma comunidade sem escrita, no mundo da escrita - (WILLIAMS, Patrik, "L'Ecriture entre l'oral et l'écrit. Six Scènes de la vie tsigane en France », In FABRE, Daniel. Par écrit. Ethnologie des écritures quotidiennes. Paris : Éditions de la Maison des Sciences de l'Homme, pp. 60-82.) procura mostrar-se a impossibilidade de conservar leituras excessivamente binárias entre oral e escrito. Na verdade, os dois modos de expressão antes de se oporem coexistem e em alguns casos entram em concorrência ou mesmo em relação de complementaridade. A relação que mantêm não é unívoca e, por vezes, é mesmo de uma singular subtileza a que é preciso estar atento e saber avaliar. 
O fenómeno colonial nesta África sub-sahariana e sobretudo para períodos em que a colonização formal não está em curso, dificilmente pode ser vinculado a um só padrão de relação. Os níveis de interferência entre sociedades africanas e sociedade colonial são extremamente espartilhados e múltiplos, desde logo porque a própria colonização, maioritariamente assente nas franjas litorais, embora com intromissões continentais através dos caminhos e das feiras que alimentavam o tráfico, só episodicamente se constituiu como força hegemónica e homogeneizadora, no plano territorial. A possibilidade da produção de re-arranjos, e formas de bricolage ideológico-cultural, que não devem ser confundidos com mestiçagens e crioulidades, afinal a possibilidade da ocorrência de múltiplas e mutuas apropriações foi condição para a construção da relação colonial.

Quanto aos Ndembu, de facto, eles procederam a uma recepção/utilização do sistema alfabético europeu, o que lhes permitiu organizar "Arquivos de Estado" (e a designação é dada pelos próprios) onde foram guardados, ao longo de quatro séculos, documentos escritos resultado da troca de correspondência entre os chefes africanos e as autoridades portuguesas coloniais e também entre as próprias elites políticas africanas. Trata-se portanto de um corpus documental composto por alguns dos arquivos dos Estados Ndembu, cujos autores são indivíduos identificados, detentores de autoridade, com objectivos de acção política datada. Isso permite, do ponto de vista da pesquisa, ultrapassar o carácter altamente normativo e idealizado das tradições orais que costuma estar na base dos estudos sobre estas sociedades. O processo a que me refiro é de uma enorme complexidade e foi objecto de um projecto de investigação a que me entreguei com a minha colega Ana Paula Tavares durante alguns anos. ${ }^{4}$ Irei, aqui, procurar descrever alguns aspectos desse processo, e tentar, ao mesmo tempo, fundamentar a ideia de que é pela via do poder que a escrita se vulgariza entre os africanos, pelo que será ao nível da própria organização política africana que a escrita revela implicações mais originais. A investigação que entretanto desenvolvi sobre a política de inspiração iluminista em Angola - com um amplo investimento nos arquivos de Lisboa e Luanda - enriqueceu estas problemáticas. Revelou a ampla presença da escrita dos Ndembu, mas também de alguns dos

\footnotetext{
${ }^{4}$ SANTOS, Catarina Madeira e TAVARES, Ana Paula. Africae Monumenta, 2002.
} 
sobas do planalto de Benguela, nas chancelarias coloniais e a maneira como esta aprendizagem da escrita pelos africanos permitiu a circulação eficaz de informação política e administrativa, entre burocracias africanas e coloniais (nos seus vários níveis, do periférico, ao mais central), e como se estabeleceram rotas burocráticas com recurso a uma retórica conhecida e reconhecida pelos dois lados, para assim garantir a comunicação e estabelecer relações de poder através da escrita. Neste artigo desenvolverei três ideias fundamentais:

1 - O primeiro contacto africano com a escrita apreende-a como expressão do poder do outro, isto é, dos portugueses. A escrita subjaz ao próprio auto de vassalagem, visto como objecto formal e simbólico de poder que institui uma relação de subordinação do estado africano vassalo perante o governo estabelecido em Luanda.

2 - Uma segunda fase tem a ver com a própria prática da vassalidade e permite que a escrita/símbolo se revele aos africanos como instrumento ou tecnologia intelectual, ideologicamente manipulável em função dos interesses dos sujeitos que estão habilitados a usá-la. É aqui que se situa a integração intelectual da escrita e, com ela, se localiza uma certa aprendizagem da organização burocrática do poder político, em articulação com as instituições africanas. O uso deliberado da escrita, pelo lado africano, como instrumento de comunicação com o poder colonial, e entre elites africanas, produz-se através da apreensão de fórmulas e da lenta sedimentação de rotas burocráticas, com vista a produzir efeitos na sociedade colonial e no interior das sociedades locais.

3 - Numa terceira etapa a que este processo conduz, a escrita é de novo convertida ao estatuto de insígnia de poder, mas agora dentro da lógica do sistema político africano, cujas estruturas se encontram definitivamente vinculadas à escrita. De símbolo do poder do outro (poder colonial), a escrita convertese em símbolo do poder dos Ndembu (do poder africano).

\section{1.}

A primeira forma da escrita com que os estados Ndembu tomaram contacto foi a do poder. Poder é escrita e escrita é poder. Desde o final do século XVI (o primeiro exemplo data de 1582), a afirmação da soberania portuguesa, a partir do governo central de Luanda e perante os potentados africanos 
estabelecidos, socorreu-se do instrumento jurídico, já amplamente experimentado nas relações com os Estados asiáticos, que são os tratados de vassalagem. ${ }^{5}$

Os chefes africanos, que se tornavam vassalos do rei de Portugal, submetiamse a um acto solene e público que tinha a sua expressão mais formal na produção de um documento escrito. A fixação deste acto legal era indispensável. A conclusão de um tratado de vassalagem assumia uma dupla forma: um acto oral e um acto escrito. $\mathrm{O}$ acordo celebrava-se na presença de duas pessoas com poderes de soberania próprios ou delegados: o rei de Portugal, representado pelo seu governador em Angola ou outra autoridade portuguesa com poderes competentes (caso dos capitães mores dos presídios, ou os chefes dos concelhos ou distritos, divisões administrativas de carácter mais amplo), e o rei ou chefe africano. No momento das negociações e fixação das condições do tratado, a autoridade africana podia ser representada por uma embaixada, mas o tratado em si mesmo só ganhava força legal com a assinatura aposta pelo próprio rei africano e a execução por este dos actos simbólicos inerentes. Nesta cerimónia o documento escrito, previamente preparado - o auto de vassalagem propriamente dito - era lido em voz alta. Por outro lado, os actos ou gestos simbólicos de legitimação ligados à celebração do contrato, "a encomenda e a investidura" (cuja origem radicava na Europa medieval, se bem que neste contexto o seu sentido primeiro sofresse uma necessária reelaboração) eram articulados com cerimónias gestuais de origem africana. Assim, no ritual da encomenda o cerimonial europeu passou a ser substituído por um conjunto de atitudes procedentes dos costumes locais. A genuflexão do rei vassalo, no momento em que pronunciava o juramento, foi substituída por uma expressão local de sujeição e agradecimento - os sobas batiam as palmas, pondo as mãos na terra e depois no peito, enquanto juravam ser leais vassalos ao rei de Portugal. À encomenda seguia-se a investidura do vassalo, que se designou em Angola desde o século XVII por undamento, a qual, por seu turno, se subdividia em dois actos: a cerimónia do peso, directamente extraída da tradição africana e durante a qual o vassalo era coberto de pemba, simbo-

\footnotetext{
${ }^{5}$ Para Angola, vide HEINTZE, Beatriz. Luso-african feudalism in Angola? The vassal treaties of the 16th to the 18th century. Separata da Faculdade de Letras da Universidade de Coimbra, Coimbra, Instituto de História Económica e Social, 1980; para o Estado Português da Índia, vide SALDANHA, António Vasconcelos. Iustum Imperium. Dos tratados como fundamento do Império dos portugueses no Oriente. Estudo de História do Direito Internacional e do Direito Português. Lisboa, Fundação Oriente, 1997.
} 
lizando com isso a instalação legítima no seu território tradicional; e por fim a chamada cerimónia do vestir.

O contrato de vassalagem, documento escrito, continha, por sua vez, um catálogo de direitos e obrigações a cumprir por ambas as partes. Em troca de paz e protecção, os Ndembu juravam fidelidade ao rei de Portugal, o que pressupunha cumprir e respeitar as leis do governo; pagar os impostos (o dízimo); auxiliar o governo na guerra com forças militares; abrir os caminhos e permitir o livre-trânsito ao comércio; receber os empregados públicos, civis, eclesiásticos, judiciais e militares; não acoitar foragidos e viver em paz com os seus povos.

A escrita começou, portanto, por ser o meio utilizado pela Coroa portuguesa para os contactos oficiais com os chefes africanos. Os sobas ou ndembu avassalados encontravam no registo escrito a legitimação do seu poder pelas autoridades coloniais e ganhavam consciência da necessidade de guardar essa documentação como símbolo da relação estabelecida. O registo em papel salvaguardava assim para o exterior aquilo que era válido oralmente nas relações puramente africanas. Desta forma, os africanos, mesmo antes de saberem ler e escrever e de reconhecerem à escrita a função de instrumento de comunicação, foram compelidos a considerar o carácter vinculativo, fixo e perene do que é gravado sobre o papel. Antes de ser instrumento de comunicação, a escrita foi utilizada e apreendida como um símbolo do poder político europeu.

A escrita é apreendida como símbolo antes de ser entendida como instrumento intelectual. O seu aparecimento é instantâneo, não resulta de uma aprendizagem laboriosa, quer dizer de um processo intelectual. Há um momento em que o processo de incorporação da escrita está em suspensão, permanece inacabado, para só depois ser finalizado, quando a escrita/símbolo abre lugar à escrita/como processo intelectual. E o primeiro passo não conduz necessariamente ao segundo. O processo pode permanecer inacabado, preso à função simbólica, que é também sociológica, dispensando a função intelectual. Essa hipótese de "suspensão", ou de cristalização da "importação da escrita já constituída" não será exclusiva dos Ndembu, e a prova-lo está a narrativa que LéviStrauss faz em Tristes Tropiques, ${ }^{6}$ depois retomada por Jacques Derrida, do chefe Índio dos Nambikwara que, observando como o antropólogo usa o papel

${ }^{6}$ LÉVI-STRAUSS, 2005 (1959): Tristes Tropiques, Paris: Plon, 2005 (1955), pp. 347-360. 
para nele gravar as aranhas da escrita, não hesita em imitá-lo, garatujando no papel branco mensagens indecifráveis, mas que, simbolicamente, lhe permitiam um distanciamento em relação ao seu povo e uma equiparação a quem chegava de fora: "il a immédiatement compris son rôle de signe, et la supériorité sociale qu'elle confère".?

A modalidade do estabelecimento de tratados de vassalagem como forma de domínio, pelo menos nominal sobre os poderes africanos do interior angolano teve lugar desde o século XVII até à década de 20 do século XX. O mesmo aconteceu com as fórmulas contidas nesses autos de vassalagem. Elas são entre si muito iguais, extremamente repetitivas e regulares ao longo do tempo. Esta continuidade textual e institucional exigiu um exercício intenso da cultura da vassalidade e contribuiu de forma decisiva para uma vulgarização de todo o vocabulário jurídico-político de raiz feudo-vassálica e da própria escrita como forma de exercício do poder. É o próprio estatuto político-jurídico de vassalo que exige aos Ndembu a introdução de uma estrutura burocrática que lhes permita sustentar esse mesmo estatuto. ${ }^{8}$

\section{2.}

Assim, o segundo ponto desta comunicação tem a ver com a prática da vassalidade, em si. A escrita passa a estar associada à cultura política que os próprios tratados trazem consigo e assim se explica que a documentação dos arquivos de Estado dos Ndembu, trocada entre estes e o Governador de Angola ou os poderes administrativos intermédios trate, na sua grande maioria, questões relativas às relações de vassalagem. ${ }^{9}$ A correspondência serve para garantir o

\footnotetext{
${ }^{7}$ DERRIDA, Jacques. De la grammatologie, Paris: les Éditions Minuit, 2002, p.185.

${ }^{8}$ As práticas da escrita começam por andar ligadas às relações de poder e têm, portanto, um carácter oficial e público. As questões privadas aparecem sobretudo ao longo do século XIX.

${ }^{9}$ Poderia apontar aqui variadíssimos exemplos. Para evidenciar a profundidade histórica destes fenómenos cito um exemplo do século XVII (Capítulos do juramento que prometeu guardar o Duque de Hoando, D. António Afonso, Arraial do alojamento do rei do Congo, 11 de Janeiro de 1666, Arquivos de Angola, vol.I, n¹, 1933, s.p.) e um outro do final do século XVIII, Carta do Governador Manuel de Almeida Vasconcelos para Dom João Manuel Silvestre, nomeado Gombe Amuquiama Samba Aquine, 26 de Novembro de 1791, AHU, Cód. 1628 , fl. 108. Sobre a circulação dos sobas vassalos em direcção a Luanda, já no início do século XIX, Carta do governador António Saldanha da Gama para o capitão-mor de Cambambe, 31 de Março de 1809, AHNA, Cód. 3018, fl.6.
} 
cumprimento dos termos do contrato. Trata-se afinal de uma prática da vassalidade a exigir o recurso à escrita por forma a resolver assuntos com ela relacionados, assegurar a harmonia dos poderes e garantir uma certa paz diplomática, conduzida pelas regras da amizade política, com base nessa mesma vassalidade. Exemplo disso é a renovação dos autos e respectivos juramentos de fidelidade, no momento de eleição de novos Ndembu; a confirmação e repetição das cerimónias de homenagem e undamento; o pagamento dos dízimos, ou ainda o provimento regrado dos canais diplomáticos através da troca de embaixadas, e embaixadores, presentes ou simples cartas de etiqueta.

De acordo com o estipulado nos tratados de vassalagem, à maneira de etiqueta de corte e sempre que um novo governador chegava a Luanda, os diferentes sobas eram obrigados a enviar-lhe uma embaixada, de forma a confirmar a sua fidelidade junto do novo representante do rei de Portugal. Estas cerimónias, em que se confirmava o undamento, constituíam ocasião para troca de presentes e sedimentação de alianças. O não cumprimento do protocolo originava tensões, trocas de correspondência, pedindo explicações, dando justificações, e, em última instância, podia conduzir à dissolução do laço de vassalagem e até à guerra. ${ }^{10}$ A circulação entre Luanda, os presídios e os potentados africanos, por meio de embaixadas, onde seguiam grandes comitivas (com cerca de meia centena de pessoas), e embaixadores, gerava um verdadeiro corrupio. Com as embaixadas, nos seus vaivéns, circulava a escrita, as regras da burocracia, maneiras de dizer, fórmulas. ${ }^{11}$

$\mathrm{Na}$ sequência dos tratados estabelecidos e em cumprimento dos termos implícitos aos contratos, começa então a circular outro tipo de documentos

\footnotetext{
${ }^{10}$ Sobre prática da vassalidade e as embaixadas enviadas a Luanda vide SANTOS, Catarina Madeira. Um governo polido para Angola: reconfigurar dispositivos de domínio (1750c.1800), Tese de doutoramento, 2005, e em especial o sub-capítulo "Comunicação africana, rotas burocráticas e burocracias africanas".

${ }^{11}$ Sobre as múltiplas interferências entre direito colonial e direitos "africanos/consuetudinários", em Angola, e os processos de mútua apropriação e recriação (quer dizer, a maneira como o mundo jurídico africano importa e usa o vocabulário feudo-vassálico, e a maneira como o mundo jurídico colonial apropria e usa o vocabulário jurídico consuetudinário dos Ndembu ou outros, e não esqueçamos que o Governador de Angola era, também, juiz de mucanos, isto é, julgava as causa "indígenas" segundo o direito local...) vide SANTOS, Catarina Madeira. "Entre deux droits: les Lumières en Angola (1750-v.1800). Annales HSS, $60^{\mathrm{e}}-\mathrm{n}^{\mathrm{o}} 4$, juillet-aôut, p. 817-848; e idem.
} 
escritos, abrindo assim novos campos à intervenção da escrita, cuja produção decorre directamente da relação de vassalagem accionada: é o caso dos recibos, livranças ou cartas de dívida que visam o pagamento do imposto (dízimo), exigido aos sobas vassalos; ou ainda cartas que definem estratégias de aliança com o fim fazer a guerra aos inimigos comuns dos Ndembu e dos portugueses.

$\mathrm{O}$ estatuto de vassalo implica ainda nova produção escrita na medida em que supõe o enquadramento dos Ndembu dentro da malha administrativa e jurisdicional portuguesa, de que os presídios eram a sede. Os Ndembu integravam-se em divisões jurisdicionais onde se fazia justiça, e se procedia aos registos de propriedade de terras, à redacção de testamentos etc. Verifica-se o recurso à justiça portuguesa para resolver questões que se geravam entre os próprios Ndembu e que tradicionalmente eram julgados sob a forma de mucanos, isto é, como decisões judiciais oralmente pronunciadas pelas autoridades africanas. ${ }^{12}$ A recepção do direito português no quadro das instituições africanas, a aprendizagem secular de procedimentos burocráticos, ainda que muitas vezes restringida a fórmulas articuladas com as práticas implícitas às instituições do parentesco, são condição necessária para que uma retórica da colonização, assente em rotas burocráticas, se vá estabelecendo e revelando num uso continuado, para estar a funcionar em pleno na primeira década do século XIX, de tal forma que pode ser invocada pelo governo de Luanda, como uma dado adquirido, na gramática das relações. Sem querer sobrecarregar o texto com exemplos documentais, não posso deixar de propor uma carta em que se dá conta dessa aprendizagem antiga :

Em 1811 um requerimento do Dembo Caboco Cabilo merece do Governador de Angola, em exercício uma chamada de atenção para os trâmites do protocolo e as regras da escrita:

falta de atenção com que escrevetes [sic] ao capitao-mor como se mostra da sobre carta que lhe dirigistes faltando com aquele tratamento civilidade e subordinação com que todos os Dembos e Souvas tem escrito aos seus capitães mores chamando-os de vossa merce mostrandolhes o maior respeito, parece que sendo esse estilo muito antigo e

${ }^{12}$ Arquivo Histórico Nacional de Angola, Luanda, cod. 240, f. 82v, Luanda, 5 de Outubro de 1811. 
louvável devia ser por vós praticado em prova da vossa obediência e bondade de animo [...]. ${ }^{13}$

Há uma questão de cronologia, mas também de geografia, a ter em conta. Na zona dos Ambundos, e em especial no caso dos Dembos, dada a antiguidade das relações entre culturas europeia e africana, não surpreende que logo em 1767, se encontre um requerimento envolvendo dois africanos. ${ }^{14}$ Porém, à medida que se avança para o final do século, não só esse fenómeno se intensifica como se alarga aos sobas do planalto de Benguela, em especial o Bailundo. Ainda numa província tão remota como Quilengues, as representações dos africanos junto do capitão-mor, tendo em vista a reposição de situações julgadas injustas ou incorrectas, ocorrem diariamente: “...quase todos os dias havia representações de negros ....". ${ }^{15}$ E é verdade. Pouco sentido faz debitar aqui as listas de requerimentos que fui coleccionando, mas faz sentido sublinhar que essa catadupa, essa "febre" da burocracia está lá.

${ }^{13}$ Carta de D. Francisco Inocêncio de Sousa Coutinho para D. Paulo Sebastião Francisco, Cheque Dembo Caculo Cacahenda, 19 de Setembro de 1767, Arquivo Histórico Militar, $2^{\text {a }}$ divisão, $2^{\circ}$ secção, Cx.1, nº 4 .

${ }^{14}$ Arquivo Histórico Nacional de Angola, Cód. 442, fl. 220 v . Oficio para o general do Estado de 21 de Março de 1802. Podem-se ainda coligir dezenas de exemplos: “(...) dois requerimentos que me [Governador] fizeram os macotas do soba Ndambo Aquioza (...)",Carta para o regente de Ambaca, 24 de Setembro de 1808, Arquivo Histórico Nacional de Angola, Cód. 91, fl. 103. As respostas do Governador dirigidas aos presídios citam e descrevem variadíssimos tipos de requerimento: requerimento do Dembo Mutemo Aquiguengo, D. Agostinho Manuel Silvestre, contra o capitão-mor de Encoge, acusando-o de se intrometer no conhecimento das ouvidas que se passavam entre os seus filhos, 13 de Janeiro de 1813, Arquivo Histórico Nacional de Angola, códice 92, fl.12; requerimento do soba Casse Candala, Cristóvão André, para ser restituído à sua antiga posse, 7 de Fevereiro de 1814, Ibidem, fl. 15; Requerimento do soba Ndambi Aquiosa, D. Tomás Diogo, mais o termo de ouvida dos macotas do estado, feito pelo capitão-mor, em que declaravam que queriam no Estado um outro soba que fora undado pelo seu antecessor, 8 de Fevereiro de 1814, Ibidem, fl. 15v; Requerimento do reino do Dongo, contra o cabo de esquadra, 28 de Fevereiro de 1817, Arquivo Histórico Nacional de Angola, códice. 92, fl. 18; Requerimento de pretos calçados, para serem isentos do serviço nas obras reais, 12 de Novembro de 1816, Ibidem, fl. 12v. Um exemplo de negociação através da burocracia encontra-se na Carta para o soba Quingue, Dom Sebastião Potentado do Bailundo, transcrito para a Caixa 53 do Arquivo Histórico Ultramarino, 1769, Biblioteca Nacional de Lisboa, códice. 8573, fl. 40v-41v .

${ }^{15}$ MILLER, Joseph. Poder Político e Parentesco. Os antigos estados mbundu em Angola, tradução de Maria da Conceição Neto, Luanda: Arquivo Histórico Nacional de Angola, Ministério da Cultura,1995, p. 55 e ss. 


\section{3.}

A apreensão africana de uma relação entre escrita e Estado garantida pelos tratados de vassalagem parece não ter desencadeado de imediato, situações de conflito entre o sistema das linhagens e as concepções de burocracia e de organização política implícitas ao sistema colonial. Estas relações de vassalagem não chegavam de facto a perturbar os fundamentos da organização política interna dos Ndembu, e ao mesmo tempo, funcionavam como instâncias de legitimação dinâmica do poder africano. O próprio vocabulário político-jurídico de raiz feudo-vassálica passou a ser utilizado na definição das relações entre os Estados africanos, enquanto o estatuto de vassalo veio a revestir-se, paradoxalmente, de uma ambiguidade que se revelava igualmente conveniente aos portugueses e aos africanos e, em algumas circunstancias, altamente interessante para os próprios Ndembu. Os enunciados (a forma que assume a ideia) diferem em relação à enunciação (a idéia ou compromisso político que o enunciado refere), mas o reconhecimento mútuo da sua (do enunciado) validade garante a hipótese de negociação. A verdade é que, durante décadas de colonização, há uma retórica comum que se vai estabelecendo de parte a parte, e quando ela é quebrada ou desrespeitada, a comunicação deixa de se estabelecer.

Ao invocarem o seu estatuto de vassalos, os sobas conservam no entanto uma autonomia política capaz de manter-se na sombra, desde que não faça intervir os poderes tutelares. Pode assim entender-se que no final do século XIX, e numa conjuntura latente de conflito, os Ndembu façam recurso a uma dupla vassalidade, invocando uma antiga ligação de tipo vassálico ao reino do Congo, para se oporem a certas pretensões de Luanda. Mais interessante ainda é verificar de que forma as hierarquias da vassalagem vêm acrescentar-se às hierarquias africanas. $\mathrm{O}$ uso repetitivo da cultura da vassalagem origina a sua validação e revitalização fora do contexto original, isto é, fora das relações com o poder colonial, e acaba por lhe conferir novos significados e efeitos, desta vez no contexto africano endógeno onde, como já referiu Joseph Miller, uma qualquer definição de estruturas de tipo estatal exige a consideração de aspectos de sociedade ditos "não políticos". ${ }^{16}$ É assim que o tema da vassalidade

\footnotetext{
${ }^{16}$ SANTOS, Catarina Madeira e TAVARES, Ana Paula, Africae Monumenta, 2002, p. 440. A analogia com outras profissões é sugerida pela leitura de Miller que afirma para o caso dos caçadores, que estes se entendiam e tinham importância para além dos limites das estruturas de parentesco, Cf. MILLER, Joseph, Poder político e parentesco, p. 51, 52.
} 
aparece, na documentação interna, em perfeita articulação com um discurso da oralidade onde sobressaem as hierarquias tradicionais: a hierarquia determinada pela senioridade; ou a indicação das relações de parentesco como metáforas das relações políticas etc.

Ora é esta estratégia das vassalidades que vai permitir aos africanos articular o vocabulário político africano da oralidade e o vocabulário político colonial da palavra escrita. Ela é também o reflexo da interferência entre duas formas de entender e exercer o poder. A grande originalidade da história das instituições políticas Ndembu, na construção dos seus estados e nas relações entre estados africanos, consistirá, assim, no facto de lhe introduzirem estruturas burocráticas baseadas em registos e em instruções escritas. E será desta forma que, no aparelho de estado tradicional - identificado com o ndembu ou soba e seus macotas - passa a impor-se, desde o século XVII, a figura exemplar e reveladora do secretário. A sua presença é central em todo o processo de aprendizagem da escrita do poder. A ele se reconhece uma posição hierárquica equivalente à das dignidades tradicionais e cabem-lhe os contornos de figura chave no desenvolvimento das relações diplomáticas com as autoridades portuguesas. Configura-se assim, nas estruturas Ndembu, um quadro que admite e exige até a emergência de novos estatutos. Remeto para uma hipótese levantada num trabalho anterior onde se aventa a hipótese de em certas alturas o posto de secretário poder constituir uma forma de estatuto de poder à margem das estruturas do parentesco, como o eram outras profissões, de que são exemplo os caçadores. ${ }^{17}$ O secretário passa, de facto, a estar representado em momentos politicamente prestigiados (assinatura de tratados de paz, embaixadas dirigidas ao Governador em Luanda) ao dos grandes dignitários de corte, os macotas.

Foi na sequência de tudo isto que cada uma destas chefias Ndembu veio a criar chancelarias que passaram a funcionar como repositórios da memória política e onde encontramos, ao lado dos tratados e outros documentos ligados à presença colonial, correspondência vária produzida a propósito da própria política interna das chefias dos Ndembu.

\footnotetext{
${ }^{17}$ Referência em documentação presentemente em estudo e que será publicada proximamente no volume II dos Africae Monumenta.
} 
Através da escrita, assim, os africanos apreendem a organização do Estado, identificado com o Arquivo e com os próprios materiais da escrita (secretaria, e respectivo aparato). Não só existe, portanto, uma escrita de Estado, como a escrita acaba por ser o próprio Estado. Não é por acaso que nos documentos gravados pelos secretários, em nome dos Ndembu, nos topamos com a palavra "trastesalio". " 18 "Trastesalio" não tem significado no português ou no kimbundu, corresponde a um neologismo e equivale a uma forma usada pelos Ndembu para definir as coisas do Estado. Os arquivos dos Ndembu ganham de tal forma o estatuto de insígnias de poder que, em períodos de guerra, os arquivos figuram entre os primeiros objectos de confisco.

Ao longo de todo o século XIX e já no período de confronto com uma política colonial de campanhas militares, depois da Conferência de Berlim (1884/85), os próprios temas de política africana aparecem tratados nas cartas inter-Ndembu, em questões, por exemplo, de eleição de novos Ndembu; renovação das cerimónias da vassalagem; processos de sucessão entre Ndembu ligadas a disputas entre linhagens; informações acerca da origem de títulos políticos e respectiva legitimidade; discussões sobre insígnias de estado; envio de embaixadas etc.

A escrita constitui-se, definitivamente, como um elemento de inovação política que actua ao nível das estruturas estatais Ndembu, sabendo acrescentarse às formas de organização e legitimação já existentes, aprendendo a coexistir com elas e (apreendendo) sofrendo até as mesmas formas de transformação. 